\title{
Accounting management model of agribusiness: engineering tools for accounting and analysis
}

\author{
Tatyana Kushnarenko ${ }^{1}$, Petr Shumilin ${ }^{1, *}$, Oksana Yuryeva $^{1}$, Tatyana Medvedskaya ${ }^{1}$, and \\ Elena Zaporozceva ${ }^{1}$ \\ ${ }^{1}$ Don State Technical University, Gagarina Sq., 1, Rostov-on-Don, Russia
}

\begin{abstract}
The problem of improving the management of agribusiness at the micro level in terms of accounting and engineering support is being solved. The application of an accounting management model that provides the generation of economically useful information based on the use of accounting and analytical mechanisms that operate in accordance with the principles of flexibility, relativity, and adaptability is proposed.
\end{abstract}

\section{Introduction}

Agribusiness is a dynamically developing sector of the economy that ensures the country's food security. So, in 2016, Russia took first place in the world economy in wheat exports; in 2017, a record harvest of grain was harvested. The share of agriculture in the country's GDP is steadily growing, steadily approaching 5\%. Agribusiness is showing growth dynamics despite the crisis in the economy. In 2015, the agricultural industry became the leading sector, showing production growth with an increase of $3.5 \%$. Agribusiness includes various varieties of plant growing, livestock and poultry, as well as enterprises for processing and selling finished products $[1,2,3]$. The main objective of the development of the domestic economy is the formation of structural shifts in favor of increasing the share of manufacturing and agriculture, which creates the prerequisites for the implementation of the import substitution plan and the formation of economic sovereignty, avoiding the dominance of the raw materials sector [4,5,6]. "All this requires the formation of new methodological approaches to the assessment and management of dynamic transformations of this type, their essential and meaningful transformation" [7].

Current trends in the functioning of economic life, the strengthening of competitive interaction of business entities aimed at achieving competitive advantages and increasing the profitability of agribusiness require the use of fundamentally new methodological approaches to management. The above situation causes an objective need to use a relaybased information system, which allows adequately and in a timely manner providing the needs of managers of various levels and owners with data that are indicators for determining the agribusiness strategy and solving production, processing and marketing

* Corresponding author: petr_shumilin_ml@mail.ru 
activities. "Enterprise management is a complex and multi-level process of coordination and regulation of its activities in order to increase the profitability and effectiveness of the enterprise." [8]

The specifics of agribusiness is determined by a wide range of factors of internal and external nature and is manifested in various directions of the functioning of value chains, "the most important component of modernizing the agro-industrial potential of Russia and its regions is the large-scale introduction of innovations that ensure the transition to promising technological patterns, it is of particular importance to develop adaptive mechanisms for the effective management of these processes from the perspective of a strategic approach." [9]

All of the above encourages a deep scientific analysis of existing managerial and entrepreneurial concepts and paradigms taken as a basis in the construction of agribusiness, consideration of the place and role of such critical management components as accounting, analysis, control, research and generalization of the methodology used in Russian and foreign practice, formulation of reasonable proposals for improving the accounting and analytical mechanisms for managing agribusiness.

The study of theoretical, methodological and organizational problems of accounting and analytical support for management is noted in the works of Russian scientists R.A. Alborov, S.A. Boronenkova, M.A. Vakhrushina, A.V. Glushchenko, E.M. Dusaeva, V.B. Ivashkevich, O.D. Kaverina, T.P. Karpova, V.E. Kerimov, N.P. Kondrakov, S.N. Kolesnikov, E.V. Kuznetsova, A.Kh. Kurmanova, G.M. Lisovich, O.E. Nikolaeva, S.A. Nikolaeva, G.I. Pashigoreeva, V.F. Paliy, Y.V. Sokolov, L.S. Sosnenko, V.P. Suits, S.A. Stukov, V.I. Tkach, V.T. Chaya, I.N. Chernykh, A.D. Sheremet, T.G. Sheshukova, L.I. Khoruzhiy, D. Khan, and others, as well as foreign scientists C. Drury, E. Norin, J. Foster, and others.

The purpose of this scientific work is to improve accounting and analytical mechanisms based on the established accounting model for agribusiness management, including accounting and analytical mechanisms for the formation of relevant information ensuring management decisions and aimed at improving management efficiency to meet the needs of the current stage of development of the domestic and the global economy, the formation of a decision support system for agribusiness management based on monitoring necessary indicators of financial and economic situation of the company.

\section{Materials and methods}

We use the method of accounting and economic modeling of agribusiness management, based on a "systematic approach and taking into account that a system is a set of interconnected elements or parts that are striving to achieve a common goal. During the study" [10], the following problems were solved:

- identified industries and sub-sectors of the economy involved in the value chain "production-storage-processing-sales" of agribusiness;

- the types of accounting, which are the structural elements of modeling and forming the interface for the collection of primary accounting information, are determined;

- the operating principles were selected in accordance with the current needs of agribusiness and the characteristics of the current economic situation;

- $\quad$ the functions of the accounting model aimed at meeting the needs of agribusiness are revealed;

- $\quad$ large objects of accounting, analysis, control and management are identified;

- measures have been taken to protect agribusiness enterprises on the basis of risk identification and identification of protection methods;

- $\quad$ a structured chart of accounts has been formed in order to satisfy the need for relevant 
accounting information;

- $\quad$ reporting forms are proposed;

- $\quad$ a system for monitoring indicators has been developed;

- $\quad$ accounting and engineering tools for determining forecast indicators are proposed;

- a management decision support system has been developed.

The developed model is applicable for such agribusiness sectors [11-14] as various types of crop production (flax growing, grain growing, fruit growing, potato growing, beet growing, etc.), as well as fish farming and fishing, beef cattle breeding, pig breeding, poultry farming, dairy farming, animal husbandry, meat and wool animal husbandry, reindeer husbandry. The model consists of ten interconnected blocks that ensure the functioning of the control system in the direction of the set goal, presented in Figure 1.

\section{Agribusiness}

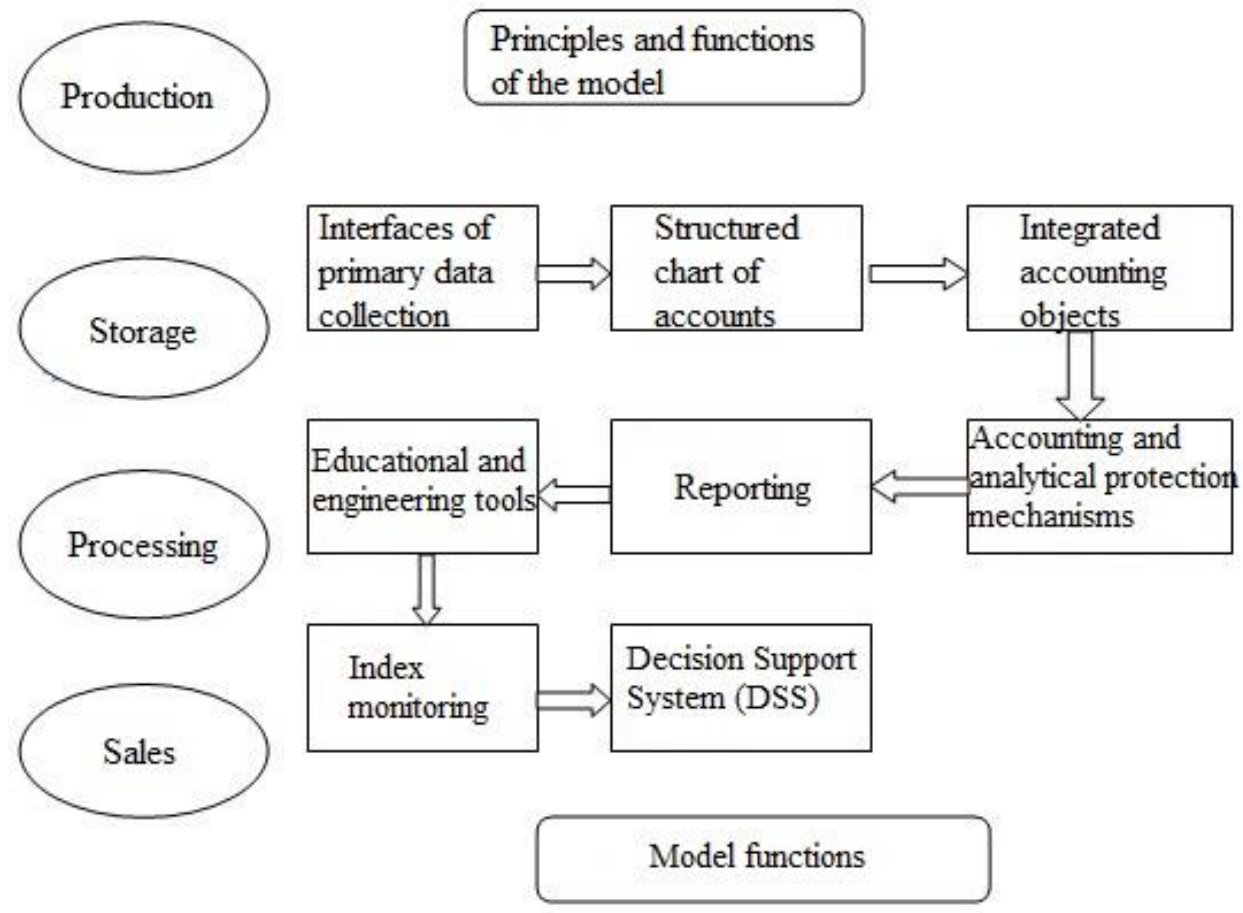

Fig. 1. Accounting management model of agribusiness.

The first block of the model - the principles of functioning, includes such principles as flexibility, relevance, adaptability. The principle of flexibility assumes that the accounting and analytical mechanisms used can easily be changed depending on changes in the goals and objectives of agribusiness without a radical change in the fundamental constants of the management system, which ultimately will lead to cost savings on modeling and implementation of the management system. Relevance - the principle of generating economically useful information, on the basis of which effective management decisions are made, leading to the achievement of the goals of the functioning of the business system. The principle of adaptability is typical for the current market situation of a large flow of changes, when the parameters of a business system can undergo changes under the influence of environmental factors. The management system we model should be able to 
quickly respond to the changes that have occurred, be prepared to monitor and reflect new phenomena and processes based on monitoring the necessary data.

The second block includes management functions that are implemented through the introduction of the accounting model developed by the authors, which include accounting, analytical, monitoring, forecasting, control, motivational, workflow, marketing. The accounting function is to collect, systematize and generalize information about all accounting objects of a financial, managerial, tax, and other nature. Analytical function allows forming an algorithm for calculating the financial and economic indicators of agribusiness activity based on accounting data. The monitoring function consists in the permanent collection of information according to the given parameters and its presentation in a form that is relevant for making management decisions. The implementation of the forecast function is associated with the formation of forecast performance indicators. The control function is to generate information on the degree of fulfillment of planned indicators, on the compliance of current indicators with forecast indicators, on the efficiency of resource use, on the activities of various structural units, etc. depending on the object of control. The workflow function allows organizing the document management of agribusiness enterprises, integrated with the collection of primary information based on modern digital technologies. The motivational function allows taking into account and assessing the degree of fulfillment of the labor contract, as well as the contribution of each employee to the development of agribusiness, which will determine the fair remuneration. Implementation of the marketing function is aimed at collecting information about the market in terms of prices and types of goods, maintain a database of counter-agents in terms of buyers, advertising platforms, which will increase sales efficiency.

The third block of the model is an interface for collecting primary information, which can be recorded by various types of accounting integrated in a single digital agribusiness management platform. These include financial, managerial, strategic, forecasting, tax, and statistical accounting. The same data can be primary information for different types of accounting or for one, depending on the problems being solved. This block is oriented to the goals and objectives of the generated information, to users. So, financial accounting is intended for the collection and processing of information in accordance with the requirements of the law, and the presentation of information to external users in the form of officially approved statements. Management accounting is focused on generating information on cost centers for internal managers; strategic accounting allows reflecting the influence of external macro environment factors on the accounting and analytical parameters of agribusiness. Tax accounting is focused on the collection, processing and synthesis of information in order to generate tax returns. Forecast accounting is aimed at taking into account the forecasted hypothetical business operations in a certain time horizon: 3 months, 6 months, 1 year.

The fourth block allows identifying integrated management objects. The model we developed allows applying accounting and analytical mechanisms to such management objects as activities, business segments, business processes, value chains, profit centers, which allow us to determine the ratio of costs and obtained financial result, return on invested capital. The organization of accounting in the context of integrated objects will increase the analytical accuracy of information in the static and dynamic aspects, consisting in assessing the ratio of invested capital and the result obtained, assessing the costs incurred and the income received. "In addition, the concept of the types of activities is based on the theoretical aspects of business operations and the comparison of its cost with the market price" [15].

The function of the fifth block is the protection of agribusiness, which is an accounting and analytical risk management mechanism. It should be noted that agribusiness enterprises are subject to a combination of risks, probably more than other sectors. First of all, it is 
necessary to highlight the natural and climatic risks leading to crop failure, the death of livestock and crops due to epidemics, and the dynamic market conditions leading to price fluctuations. The accounting and analytical mechanism consists in taking into account the risk situation, assessing its impact on assets through hypothetical accounting entries, determining the types of reserves and the sources of their formation, generating analytical indicators.

The sixth block of the proposed model is the formation of an n-dimensional structured chart of accounts (the dimension is denoted as $i=1, n$ ) that meets modern criteria and requirements. We propose the formation of a multi-level chart of accounts, ensuring the implementation of the types of accounting indicated in the first block of this model, based on the principles of operation supported in the second block, which provides for the model functions ( 3 block) to obtain information on integrated objects (4 block). A structured chart of accounts in agribusiness allows the use of first-order accounting items "Activity segments", including geographical, consumer, and regional segments; 2nd-order accounting items "Strategic activity vectors" generating information on the parameters of new markets, innovative types of products, and other areas of agribusiness development. "Internal centers" are 3rd-order accounting items that generate information about cost centers, responsibility centers, profitability centers, business processes; 4th-order accounting items "Types of products", including types of crops grown, livestock, processed products, etc., depending on the specifics of the enterprise; 5th-order accounting items including income, expense, financial results, and i-order accounting items.

The seventh block allows providing relevant information in the form of accounting reports. It should be noted that "an important and urgent problem in the preparation of reliable and complete financial statements, which could satisfy all user requests, is the inclusion of non-financial data in the financial statements. The latest software packages allow solving this problem by expanding the list of details in the applied directories and documents" [16]. The financial statements are official in nature and comply with the current regulatory framework, management reporting meets current information needs about the objects of management.

The eighth block is the use of accounting and engineering tools. The method of the accounting engineering, which consists in dynamically adapting the accounting system for the urgent needs of agribusiness management, is aimed at using analytical tools, the theoretical basis of which is to determine aggregated and disaggregated property indicators. "The methodological basis of accounting engineering is disclosed through a system of derivative balance sheets, and the information basis is disclosed in a structured chart of accounts adapted for the business model." [17] "The engineering method is built on the basis of the corresponding system of instruments: zero, actuarial, hedged, immunization, fractal, strategic, reorganization, and other derivative balance sheets that allow obtaining and using information of a high degree of analyticity." [18] Accounting and engineering tools in the agribusiness management model carry out a number of functions, which are presented in table 1 .

Table 1. Functions of accounting and engineering tools.

\begin{tabular}{ccccc}
\hline Informational & Estimated & Forecasted & Protective & Aggregating \\
\hline $\begin{array}{c}\text { Generation of data } \\
\text { on agribusiness } \\
\text { potential }\end{array}$ & $\begin{array}{c}\text { The use of different } \\
\text { types of } \\
\text { assessments }\end{array}$ & Time horizons & $\begin{array}{c}\text { Protection from } \\
\text { risks }\end{array}$ & $\begin{array}{c}\text { Ownership } \\
\text { indicators }\end{array}$ \\
\hline
\end{tabular}

Monitoring indicators of the state of agribusiness allows implementing the ninth block of the accounting model. The set of accounting and analytical mechanisms used in our proposed accounting model generates indicators of solvency, liquidity, profitability, 
financial condition, synergistic effect, financial result, ownership. Monitoring is a permanent process of collecting data and presenting it in a form that is convenient for assessing and making decisions. An indicator is a signal that an information system gives about the degree to which management tasks have been achieved.

The tenth block is a decision support system (DSS). This block of the accounting model of agribusiness management allows facilitating the decision-making process by company managers on the basis of a smart interface that provides useful information in relevant form about the various aspects of agribusiness activity. The decision support system covers various time horizons of current decisions, medium-term decisions within the reporting year, and strategic decisions. This block of the model, based on accounting and engineering tools, allows generating useful information about the current activities of agribusiness based on a system of indicators and modeling future changes in indicators based on predicted results. DSS is able to reduce the risk of the "human factor" in making managerial decisions consisting in incompetence, engagement, and private interest.

\section{Conclusion}

The conclusion of this study is that the implementation of the proposed agribusiness management model based on the integration of various types of accounting and on the principles of flexibility, relevance, adaptability, performing accounting, analytical, forecasting, control, motivational functions using a wide range of integrated accounting objects based on a structured working chart of accounts using accounting and engineering tools and monitoring of analytical indicators, allows timely generation of economically useful information that ensures the adoption of effective decisions, provides improved accounting and analytical mechanisms in the direction of increasing flexibility, relevance, adaptability.

\section{References}

1. M. Gunderson, M. Boehlje, M. Neves, S. Sonka, Encyclopedia of Agriculture and Food Systems, 51-70 (2014) doi.org/10.1016/B978-0-444-52512-3.00117-0

2. G. Behzadi, M.J. O’Sullivan, T. Olsen, A. Zhang, Omega, 79, 21-42 (2018) doi.org/10.1016/j.omega.2017.07.005

3. E. Bornhofen, T. Ramires, et al., Agricultural Systems, 173, 281-288 (2019) doi.org/10.1016/j.agsy.2019.03.006

4. D. Zylbersztajn, Revista de Administração, $52 \quad 1, \quad 111-117$ (2017) doi.org/10.1016/j.rausp.2016.10.004

5. J. Vinícius de Avila Pacheco, R. Morabito, Computers \& Industrial Engineering, 61, 6, 848-857 (2011) doi.org/10.1016/j.cie.2011.05.018

6. K. Boratyńska, E. Grzegorzewska, Journal of Business Research, 89, 175-181(2018) doi.org/10.1016/j.jbusres.2018.01.028

7. A. Kuzminov, T. Medvedskaya, N. Badvan, Financial research, 1, 58, 93-101(2018)

8. V. Eremenko, T. Kantysheva, Vector of Economics, 2, 20, 4 (2018)

9. T. Kushnarenko, Economics: yesterday, today, tomorrow, 8, 339-350 (2016)

10. P. Shumilin, Naukovedenie, 4, 13, 237 (2012) elibrary.ru/item.asp?id=18822664

11. S. Florina, O. Ecaterina, Procedia Economics and Finance, 26, 272-277 (2015) doi.org/10.1016/S2212-5671(15)00851-5

12. R. Drăgulescu (Ghiţă), A.M. Ilie, Procedia Economics and Finance, 26, 272-277 
(2015) doi.org/10.1016/j.sbspro.2013.12.589

13. A. Hellmann, H. Perera, C. Patel, Advances in Accounting, 1, 29, 124-133 (2013) doi.org/10.1016/j.adiac.2013.02.002

14. P.K. Wells, Journal of Accounting Education, 42, 40-48 (2018) doi.org/10.1016/j.jaccedu.2017.12.003

15. V. Shumilina, Engineering Journal of Don, 3, 21, 822-825 (2012) elibrary.ru/item.asp?id $=18278918$

16. Yu. Obukhova, O. Yuryeva, Actual problems and prospects of economic development: Russian and foreign experience, 15, 117-119 (2018)

17. E. Zaporozhtseva, Strategic analysis in business modeling procedures, Accounting and Statistics, 4, 48, 79-86 (2017)

18. D. Brysina, V. Tkach, Izvestiya of the Rostov State University of Civil Engineering, 2 , 20, 102-108 (2015) 